\title{
TEORES DE CATEgUINAS E TEAFLAVINAS EM CHÁS COMERCIALIZADOS NO BRASIL ${ }^{1}$
}

\author{
Simara MATSUBARA², Delia B. RODRIGUEZ-AMAYA ${ }^{2, *}$
}

\section{RESUMO}

No presente estudo, foram determinados os teores de catequinas e teaflavinas em três marcas de chá verde e quatro de chá preto comercializadas no Brasil. A metodologia analítica consistiu de extração aquosa bastante simples e cromatografia líquida de alta eficiência. Foi utilizada uma coluna de fase reversa Novapak $\mathrm{C}_{18}(3,9 \mathrm{mmx} 150 \mathrm{~mm}, 4 \mu \mathrm{m})$ com um gradiente de água e metanol ambos em ácido fórmico como fase móvel. Em chás verdes, os conteúdos de catequinas (em $\mathrm{mg} / \mathrm{g}$ de folha seca) variaram substancialmente: catequina, 0,8 a 2,8; epigalocatequina, 8 a 44; epigalocatequina galato, 11 a 50; epicatequina, 2,3 a 8,5 e epicatequina galato, 3,1 a 7,3. No caso dos chás pretos, as concentrações (mg/g de folha seca) de catequinas estiveram nas faixas de: 10 a 50 de epigalocatequina, 14 a 37 de epigalocatequina galato, 5 a 9 de epicatequina e 10 a 21 de epicatequina galato. As teaflavinas apresentaram variação menor: entre 5 (para teaflavina 3'-galato) e 13 mg/g (para teaflavina 3,3'-digalato) de folha seca. Amostras de chás muito consumidas no Brasil (erva doce, camomila, erva cidreira, hortelã, boldo, mate, erva mate, maçã e morango) também foram investigadas, não sendo encontrada nenhuma catequina ou teaflavina.

Palavras-chave: chá verde, chá preto, catequinas, teaflavinas, cromatografia líquida de alta eficiência.

\section{SUMMARY}

CATHECHIN AND THEAFLAVIN LEVELS OF TEAS COMMERCIALIZED IN BRAZIL In the present study, the catechin and theaflavin levels in three brands of green tea and four brands of black tea commercialized in Brazil were determined. The analytical methodology consisted of a very simple aqueous extraction and high performance liquid chromatography. A reverse phase Novapak $\mathrm{C}_{18}$ ( $3.9 \mathrm{mmx} 150 \mathrm{~mm}, 4 \mu \mathrm{m}$ ) column was used with a gradient of water and methanol, both in formic acid, as mobile phase. In green tea, the catechin contents (in mg/g of dry leaf) varied substantially: catechin, 0.8 to 2.8; epigallocatechin, 8 to 44 ; epigallocatechin gallate, 11 to 50; epicatechin, 2.3 to 8.5; and epicatechin gallate, 3.1 to 7.3. In the case of black tea, the concentrations (mg/g of dry leaf) of catechins were in the ranges of: 10 to 50 of epigallocatechin, 14 to 37 of epigallocatechin gallate, 5 to 9 of epicatechin and 10 to 21 of epicatechin gallate. The theaflavins had less variation: between 5 (for theaflavin 3'-gallate) to $13 \mathrm{mg} / \mathrm{g}$ (for theaflavin 3,3'-digallate) of dry leaf. Samples of teas widely consumed in Brasil (anise, camomile, lemon grass, peppermint, boldo, maté, green maté, apple and strawberry) were also investigated but no catechin or theaflavin was detected.

Keywords: green tea, black tea, catechins, theaflavins, high performance liquid chromatography

\section{1 - INTRODUÇÃO}

O chá é uma das bebidas mais consumidas no mundo todo. Anteriormente, seu consumo concentrava-se em países da Ásia e Europa, panorama que vem mudando ao longo dos últimos anos. O crescente interesse pela bebida deve-se grandemente a estudos que a mostram como fonte de flavonóides e a relação inversa entre seu consumo e o risco de doenças degenerativas como câncer e doenças do coração. Diversos artigos de revisão [8, 9, 13, 14, 15, $17,22,24,28,30,31,33$ ] mostram o grande número de trabalhos abordando o assunto, embora as evidências sejam consideradas ainda inconclusivas. O impacto que a ingestão excessiva de flavonóides gera sobre a saúde foi também revisado [27], abordando principalmente a ação dos suplementos alimentares.

Estudos in vitro encontram-se bem avançados, mostrando possíveis mecanismos de ação contra o câncer, em todas as etapas do desenvolvimento da doença: iniciação,

\footnotetext{
${ }^{1}$ Recebido para publicação em 28/6/2005. Aceito para publicação em 28/4/2005 (001562)

${ }^{2}$ Departamento de Ciência de Alimentos, Faculdade de Engenharia de Alimentos, Universidade Estadual de Campinas

Caixa Postal 6121

CEP 13083-862 - Campinas (SP)

"A quem a correspondência deve ser enviada
}

promoção e propagação [8]. Vários destes trabalhos utilizaram extratos de chás, mas atribuíram o efeito protetor às catequinas e teaflavinas. Utilizando catequinas isoladas de seus extratos, HO et al. [15] mostraram, em seu estudo, a atividade antioxidante de epigalocatequina galato e NISHIDA et al. [21], a inibição do crescimento e secreção de $\alpha$-fetoproteína por hepatomas humanos também sob ação de epigalocatequina galato. A epicatequina aumentou a atividade da NADPH citocromo $c$ redutase de células cancerosas de mama [25].

Em ratos, os estudos com epigalocatequina galato são predominantes, possivelmente pelo seu teor maior dentre as catequinas em chá verde. Este composto impediu o crescimento de tumores de fígado [21] e intestino [10].

As catequinas pertencem a um grupo de polifenóis encontrados nas folhas de Camellia sinensis, matériaprima para a produção de chás verde e preto. O chá verde é uma infusão de folhas apenas secas, enquanto que o chá preto provém de folhas processadas. No processamento, as catequinas das folhas sofrem oxidação, o que é muito importante para o desenvolvimento de cor e sabor da bebida. A oxidação é enzimática por ação da polifenoloxidase presente nos vacúolos das células. Para a enzima ser liberada destes vacúolos, as folhas secas são trituradas e deixadas expostas ao oxigênio do ar [29]. Anteriormente, 
acreditava-se que o processo era fermentativo e, por este motivo, é ainda conhecido como "fermentação" para a produção do chá preto.

As catequinas são compostos incolores, hidrossolúveis, que contribuem para o amargor e a adstringência do chá verde [2]. As teaflavinas são compostos responsáveis por parte da cor (alaranjada) e sabor (adstringência) da infusão [4] de chá preto. As estruturas destes dois grupos de compostos estão representadas na Figura 1 .

No presente trabalho, foram determinados os teores de catequinas e teaflavinas em chás comercializados no Brasil.

\section{2 - MATERIAL E MÉTODOS}

\section{1 - Amostras}

Três marcas de chá verde (Camellia sinensis) e quatro de chá preto (Camellia sinensis), assim como diversas marcas de erva doce (Pimpinella anisum L.), camomila (Matricaria chamomilla L.), erva cidreira (Cymbopogon citratus (DC.) Sapf.), hortelã (Mentha piperita L.), boldo (Peumus boldus), morango (Fragaria vesca L.), maçã (Malus domestica), mate (Ilex paraguariensis) e erva mate (Ilex paraguariensis) foram compradas no mercado local (Campinas, SP). Um chá verde constituído de folhas mais velhas e rasteiras das plantas de Camellia sinensis, denominado "Ban-chá", muito conhecido e apreciado entre a comunidade oriental foi também analisado.

O chá verde propriamente dito é feito de folhas mais novas e tenras. A diferença da matéria-prima reflete-se no sabor, cor e, possivelmente, nos teores de catequinas. De todos os produtos analisados, apenas uma marca de chá verde e uma de camomila têm matéria-prima importada
(Alemanha e Argentina, respectivamente). As embalagens variaram de 9 a 1.000 g; a diferença deve-se ao fato de que as ervas mate, o ban-chá e uma das marcas de chá verde foram vendidas a granel. As demais marcas foram adquiridas em sachês. Para cada marca, três lotes diferentes foram analisados em duplicatas.

\section{2 - Padrões e reagentes}

Os padrões de (+)-catequina (C), (-)-epigalocatequina (EGC), (-)-epigalocatequina galato (EGCG), (-)-epicatequina (EC), (-)-epicatequina galato (ECG) e teaflavinas utilizados neste estudo foram adquiridos da Sigma Chemical Co. (St. Louis, EUA). As teaflavinas estavam disponíveis na forma de mistura das quatro teaflavinas (teaflavina, teaflavina 3-galato, teaflavina 3'-galato e teaflavina 3-3'-digalato), denominada de "extrato de chá". Soluções-estoque foram preparadas com metanol, em concentrações em torno de $1 \mathrm{mg} / \mathrm{mL}$, armazenadas a $-20^{\circ} \mathrm{C}$ por no máximo dois meses. Para a preparação de soluções-trabalho, pequenos volumes de soluções-estoque tiveram o metanol evaporado por fluxo de nitrogênio e os padrões redissolvidos em solução aquosa de metanol $50 \% \mathrm{v} / \mathrm{v}$.

Para cromatografia, utilizou-se água deionizada (18,2 $\mathrm{m} \mu$ ), metanol grau CLAE (cromatografia líquida de alta eficiência) adquirido da Mallinckrodt (Kentucky, EUA) e ácido fórmico, grau analítico, da Merck (Darmstadt, Alemanha).

\section{3 - Preparação de amostras}

As folhas de um mesmo lote foram misturadas e pesadas. Para manter a presença da embalagem durante a extração mesmo depois de pesadas, as folhas foram reembaladas

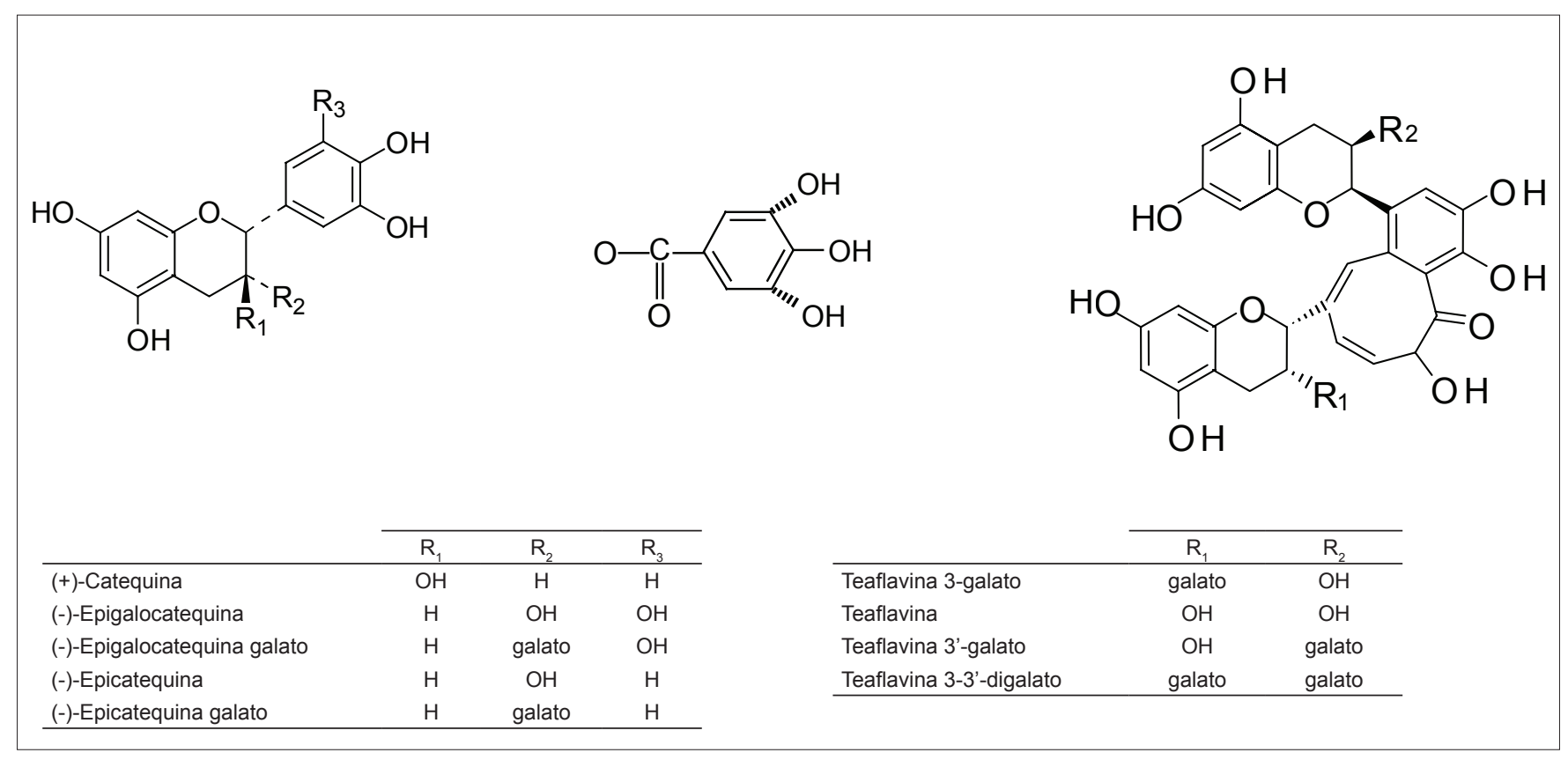

FIGURA 1 - Estruturas das catequinas e teaflavinas 
em sachês cedidos pela Der Teeladen (São Paulo, SP) e fechadas por termossoldagem de uma fita de polietileno de baixa densidade. Os novos sachês, assim como as folhas preparadas a granel, com massa de $5 \mathrm{~g}$ foram colocados em $500 \mathrm{~mL}$ água destilada fervente e deixadas por $5 \mathrm{~min}$ [12], com ligeiras agitações no início, meio e final do período. Em seguida, a mistura foi filtrada a vácuo em papel de filtro no caso de folhas a granel, ou o sachê removido da infusão e por fim, a infusão foi resfriada em temperatura ambiente. O volume foi então elevado a $500 \mathrm{~mL}$ com água destilada. A fim de melhor padronizar a extração, ao final do tempo de infusão, as embalagens foram retiradas e imersas em aproximadamente $85 \mathrm{~mL}$ de água e agitadas, sendo esta água posteriormente utilizada para completar o volume de $500 \mathrm{~mL}$. O mesmo foi feito com as amostras filtradas.

Em seguida, uma alíquota de $4 \mathrm{~mL}$ do extrato foi retirada e seu volume completado com água destilada para $25 \mathrm{~mL}$ em balão volumétrico, estando esta solução final diluída por um fator de 6,25. Aproximadamente $2 \mathrm{~mL}$ do extrato foi filtrado em filtro de politetrafluoretileno 0,22 $\mu \mathrm{m}$ hidrofóbico (Millipore, EUA) para posterior análise cromatográfica.

\section{4 - Cromatografia}

A determinação das catequinas e teaflavinas foi realizada por CLAE. As separações cromatográficas foram realizadas em coluna de fase reversa Novapak $\mathrm{C}_{18}$ (3,9 mmx150 mm, $4 \mu \mathrm{m}$ ) (Waters, Milford, MA). O equipamento foi um cromatógrafo líquido Waters, constituído de bomba quaternária modelo 600, detector de arranjo de diodos modelo 996, injetor manual Rheodyne, controlado pelo software Millennium 32.

A eluição em gradiente teve, como fase móvel solvente A, água/ácido fórmico (99,7:0,3, v/v) e solvente B, metanol/ ácido fórmico (99,7:0,3, v/v). A programação foi a seguinte: $90 \%$ A por 6 min, de 90 a $70 \%$ A em 14 min e de 70 a 55\%A em $20 \mathrm{~min}$, sempre em gradiente linear. A vazão foi de $1,0 \mathrm{~mL} / \mathrm{min}$. O volume de amostra injetado foi de $10 \mu \mathrm{L}$.

A identificação dos componentes baseou-se nos espectros obtidos entre 210 e $600 \mathrm{~nm}$ pelo detector de arranjo de diodos e nos tempos de retenção comparados com misturas de padrões injetadas diariamente. As catequinas e teaflavinas foram quantificadas a $280 \mathrm{~nm}$ por padronização externa. As curvas de calibração foram construídas obtendo-se faixas lineares para as catequinas em concentrações entre 0,6 e $205 \mu \mathrm{g} / \mathrm{mL}$, e para as teaflavinas, entre 3 e $40 \mu \mathrm{g} / \mathrm{mL}$. Os valores obtidos em $\mathrm{mg} / \mathrm{L}$ de infusão foram transformados também em mg/g de folha seca, considerando os $5 \mathrm{~g}$ de folha utilizados para a preparação da infusão.

Inicialmente, avaliou-se a possibilidade de determinar os flavonóis, catequinas e teaflavinas simultaneamente. Embora a separação cromatográfica destes três grupos tenha sido conseguida, esta tentativa foi abandonada, pois a hidrólise requerida para os flavonóis degradava as catequinas.

\section{5 - Curva padrão}

As curvas padrão para quantificação de catequinas e teaflavinas foram construídas com concentrações baseadas nas estimativas dos seus teores em chás. De uma solução-mãe em metanol contendo a mistura dos padrões, volumes de 1, 2, 3, 4 e $5 \mathrm{~mL}$ foram retirados para balóes de $5 \mathrm{~mL}$, o solvente foi evaporado e as catequinas e teaflavinas redissolvidas em metanol aquoso $50 \%$ v/v. Cada solução constituía um ponto, o qual era injetado em triplicata.

\section{3 - RESULTADOS E DISCUSSÃo}

\section{1 - Características da curva padrão}

As curvas padrão passaram pela origem e apresentaram-se lineares nas faixas de concentração em que se encontraram as amostras. A Tabela 1 mostra os dados obtidos de cada curva.

Os coeficientes de correlação foram muito bons, com valores superiores a 0,99. Para teaflavina 3'-galato, observase que o coeficiente de correlação é menor que os demais, embora a variação entre as triplicatas tenha permanecido menor que $2 \%$, assim como para os demais compostos.

\section{2 - Teores de catequinas}

Uma grande dificuldade na quantificação de catequinas é a absorção mais intensa da EGCG em relação à da EGC e da ECG em relação à da EC, embora a única diferença na estrutura seja a presença dos galatos. Assim, mesmo aparecendo como um pico bem menor que a de ECG, a EGC teve concentrações maiores e requereu uma faixa de concentração maior (Tabela 1) para calibração.

TABELA 1 - Propriedades das curvas padrão

\begin{tabular}{|c|c|c|c|}
\hline & Faixa de concentração $(\mu \mathrm{g} / \mathrm{mL})$ & Coeficiente de correlação & $\begin{array}{c}\text { Coeficiente de variação entre } \\
\text { triplicatas }(\%)^{*}\end{array}$ \\
\hline (-)Catequina & $0,6-3,1$ & 0,9998 & 0,7 \\
\hline$(+)$ Epigalocatequina & $30-143$ & 0,9963 & 0,8 \\
\hline$(+)$ Epigalocatequinagalato & $41-205$ & 0,9985 & 0,5 \\
\hline$(+)$ Epicatequina & $13-66$ & 1,0000 & 0,3 \\
\hline$(+)$ Epicatequinagalato & $5-25$ & 0,9994 & 1,2 \\
\hline Teaflavina 3-galato & $5-25$ & 0,9944 & 1,8 \\
\hline Teaflavina & $3-14$ & 0,9902 & 1,6 \\
\hline Teaflavina 3'-galato & $4-20$ & 0,9845 & 1,4 \\
\hline Teaflavina 3-3'-digalato & $8-40$ & 0,9957 & 1,6 \\
\hline
\end{tabular}



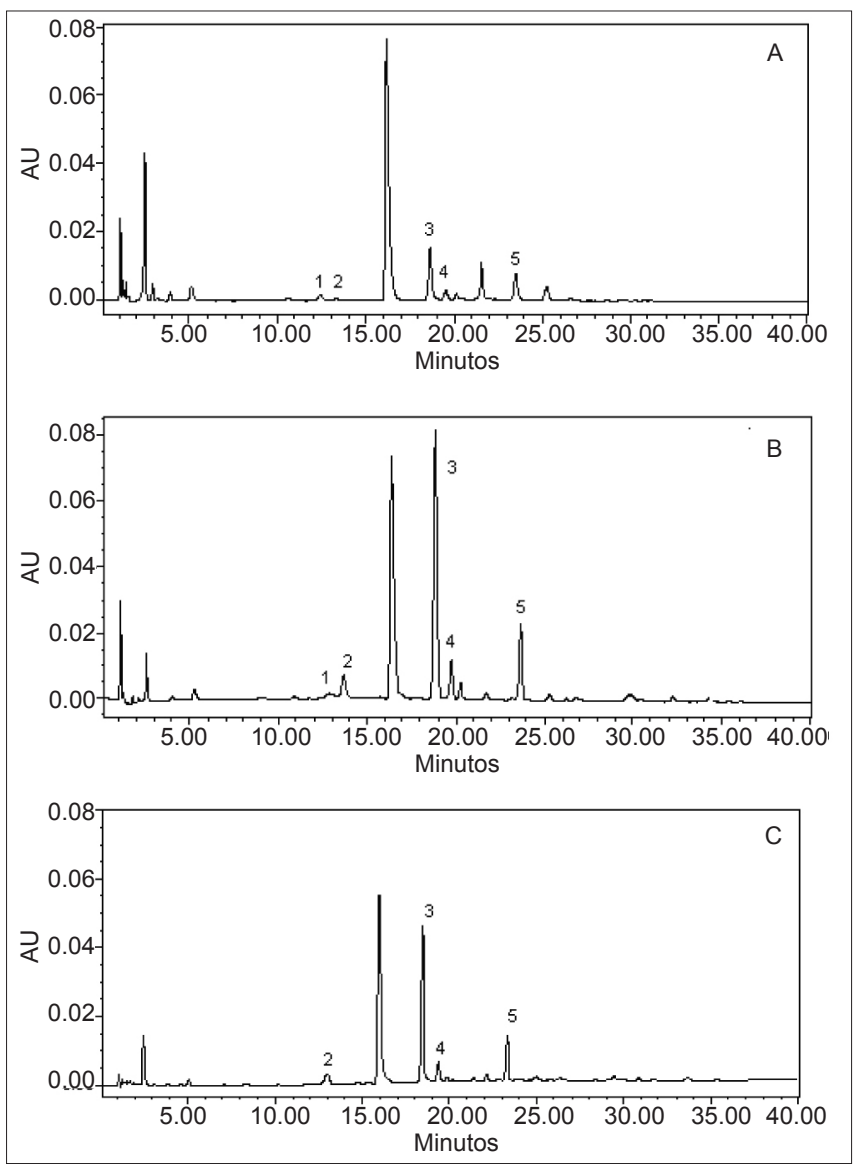

FIGURA 2 - Cromatogramas de amostras de chá verde: Ban-chá (a), chá verde marca $\mathrm{A}$ (b) e chá verde marca $\mathrm{B}$ (c). Condições cromatográficas: gradiente linear: 90\%A/6 min, de 90 a 70\%A/14 min, de 70 a 55\%A/20 min, sendo A: $\mathrm{H}_{2} \mathrm{O} /$ ácido fórmico (99.7:0.3, v/v) e B: $\mathrm{MeOH} /$ ácido fórmico (99.7:0.3, v/v) ; vazão 1,0 mL/min; detecção a $280 \mathrm{~nm}$. Picos (1) catequina, (2) epigalocatequina, (3) epigalocatequina galato, (4) epicatequina e (5) epicatequina galato
As concentrações de catequinas em chás verde e preto estão apresentados na Tabela 2 e os cromatogramas de catequinas, na Figura 2. A variação nos níveis de catequinas foi tão grande que não houve um cromatograma típico para chá verde. No entanto, todas as marcas de chás verde e preto tiveram EGCG e EGC como as catequinas principais, com a predominância de EGCG na maioria das amostras. O "Ban-chá" teve níveis menores de catequinas que as duas outras marcas de chá verde. Como esperado, os chás verdes não apresentaram teaflavinas. Em compensação, os chás pretos continham menos catequinas, indicando a transformação destas em teaflavinas por condensação.

A marcante variação nos teores de catequinas entre amostras, marcas ou tipos de chás observada no presente trabalho também é evidente em outros trabalhos (Tabela 3). Sendo dados provenientes de um mesmo trabalho, estes resultados refletem a grande variação natural entre amostras. Há, no entanto, uma diferença ainda maior e considerável entre os resultados de diferentes autores, indicando variabilidade analítica. Isso enfatiza a necessidade de aprimoramento dos métodos e mais estudos sobre estes compostos, embora vários trabalhos já foram realizados.

Há melhor concordância entre os valores obtidos em diferentes países em termos de mg/g da folha seca (Tabela 3). Os nossos resultados assemelham-se aos de DALLUGE et al. [5], PRICE \& SPITZER [23] e KHOKHAR \& MANUSDOTTIR [16] para chá verde, embora os teores obtidos pelos últimos autores para chá preto são bem menores. GOTO et al. [11] acharam níveis comparáveis de EGC e EC, mas maiores de EGCG e ECG, enquanto DING et al. [7] relataram níveis mais altos de EC, que foi a principal catequina, e ECG. LIN et al. [19] apresentaram níveis nitidamente mais altos de ECG e menores de EGC. Por sua vez, SHAO et al. [26] acharam ECG como principal catequina, além de conteúdos mais altos de EC. MATTILA et al. [20] também determinaram as catequinas de chás

TABELA 2 - Teores de catequinas e teaflavinas em chás verde e preto

\begin{tabular}{|c|c|c|c|c|c|c|c|c|c|c|}
\hline \multirow{2}{*}{ Amostra } & \multirow{2}{*}{ Marca* } & \multicolumn{9}{|c|}{ Concentração** } \\
\hline & & $\mathbf{C}^{* * *}$ & EGC & EGCG & EC & ECG & TF1 & TF2 & TF3 & TF4 \\
\hline \multicolumn{11}{|c|}{$\mathrm{Em} \mathrm{mg/g} \mathrm{folha}$} \\
\hline \multirow{3}{*}{$\begin{array}{l}\text { Ban-chá } \\
\text { Chá verde }\end{array}$} & $A$ & $1,8 \pm 0,2$ & $8 \pm 4$ & $11 \pm 3$ & $2,3 \pm 0,4$ & $3,1 \pm 0,5$ & nd & nd & nd & nd \\
\hline & $A$ & $2,8 \pm 0,3$ & $44 \pm 2$ & $50 \pm 4$ & $8,5 \pm 0,3$ & $7,3 \pm 0,6$ & nd & nd & nd & nd \\
\hline & $B$ & $0,8 \pm 0,3$ & $23 \pm 5$ & $26 \pm 2$ & $4,4 \pm 0,8$ & $4,6 \pm 0,4$ & nd & nd & nd & nd \\
\hline \multirow[t]{4}{*}{ Chá preto } & $B$ & nd & $50 \pm 2$ & $37 \pm 3$ & $8,7 \pm 0,7$ & $17 \pm 2$ & $11 \pm 1$ & $12 \pm 1$ & $7,4 \pm 0,3$ & $10 \pm 1$ \\
\hline & C & nd & $17 \pm 5$ & $14 \pm 4$ & $5,0 \pm 0,1$ & $10 \pm 4$ & $10 \pm 3$ & $8,0 \pm 2,0$ & $5,0 \pm 2,0$ & $10 \pm 3$ \\
\hline & $D$ & nd & $10 \pm 5$ & $14 \pm 8$ & $5,0 \pm 0,2$ & $10 \pm 7$ & $9,0 \pm 2,0$ & $10 \pm 2$ & $4,4 \pm 0,8$ & $8,0 \pm 2,0$ \\
\hline & $E$ & nd & $28 \pm 15$ & $28 \pm 5$ & $7,0 \pm 0,2$ & $21 \pm 3$ & $13 \pm 1$ & $11 \pm 2$ & $6,6 \pm 0,6$ & $13 \pm 2$ \\
\hline \multicolumn{11}{|c|}{ Em mg/L infusão } \\
\hline Ban-chá & $A$ & $2,8 \pm 0,3$ & $12 \pm 6$ & $18 \pm 5$ & $3,7 \pm 0,6$ & $5,0 \pm 0,8$ & nd & nd & nd & nd \\
\hline \multirow[t]{2}{*}{ Chá verde } & $A$ & $4,5 \pm 0,4$ & $72 \pm 3$ & $80 \pm 6$ & $14 \pm 0,4$ & $12 \pm 1$ & nd & nd & nd & nd \\
\hline & $B$ & $1,3 \pm 0,4$ & $37 \pm 6$ & $41 \pm 3$ & $7,0 \pm 1,0$ & $7,3 \pm 0,5$ & nd & nd & nd & nd \\
\hline \multirow[t]{4}{*}{ Chá preto } & $B$ & nd & $81 \pm 4$ & $60 \pm 5$ & $14 \pm 1$ & $28 \pm 3$ & $18 \pm 1$ & $19 \pm 1$ & $12 \pm 1$ & $17 \pm 1$ \\
\hline & C & nd & $27 \pm 8$ & $22 \pm 7$ & $8,0 \pm 2,0$ & $17 \pm 6$ & $16 \pm 5$ & $14 \pm 4$ & $8,0 \pm 3,0$ & $15 \pm 5$ \\
\hline & D & nd & $16 \pm 8$ & $23 \pm 10$ & $8,0 \pm 3,0$ & $16 \pm 10$ & $14 \pm 3$ & $15 \pm 2$ & $7,0 \pm 1,0$ & $13 \pm 3$ \\
\hline & $E$ & nd & $45 \pm 24$ & $45 \pm 8$ & $11 \pm 4$ & $34 \pm 4$ & $20 \pm 1$ & $17 \pm 3$ & $11 \pm 1$ & $21 \pm 3$ \\
\hline
\end{tabular}

Não detectado (nd), limite de detecção $=0,2 \mathrm{mg} / \mathrm{L}$

* Marcas com mesma letra foram fabricadas pela mesma empresa

*Média e desvio padrão de três lotes analisados em duplicata

**(C) catequina; (EGC) epigalocatequina; (EGCG) epigalocatequina galato; (EC) epicatequina; (ECG) epicatequina galato; (TF1) teaflavina 3-galato; (TF2) teaflavina; (TF3) teaflavina 3'-galato; (TF4) teaflavina 3-3'-digalato

A matéria-prima do chá verde marca B foi importada da Alemanha, sendo as demais amostras de produção brasileira. Ban-chá e chá verde marca A estavam a granel e as demais amostras, em sachês 
TABELA 3 - Comparação dos teores de catequinas e teaflavinas em chás verde e preto de diferentes países

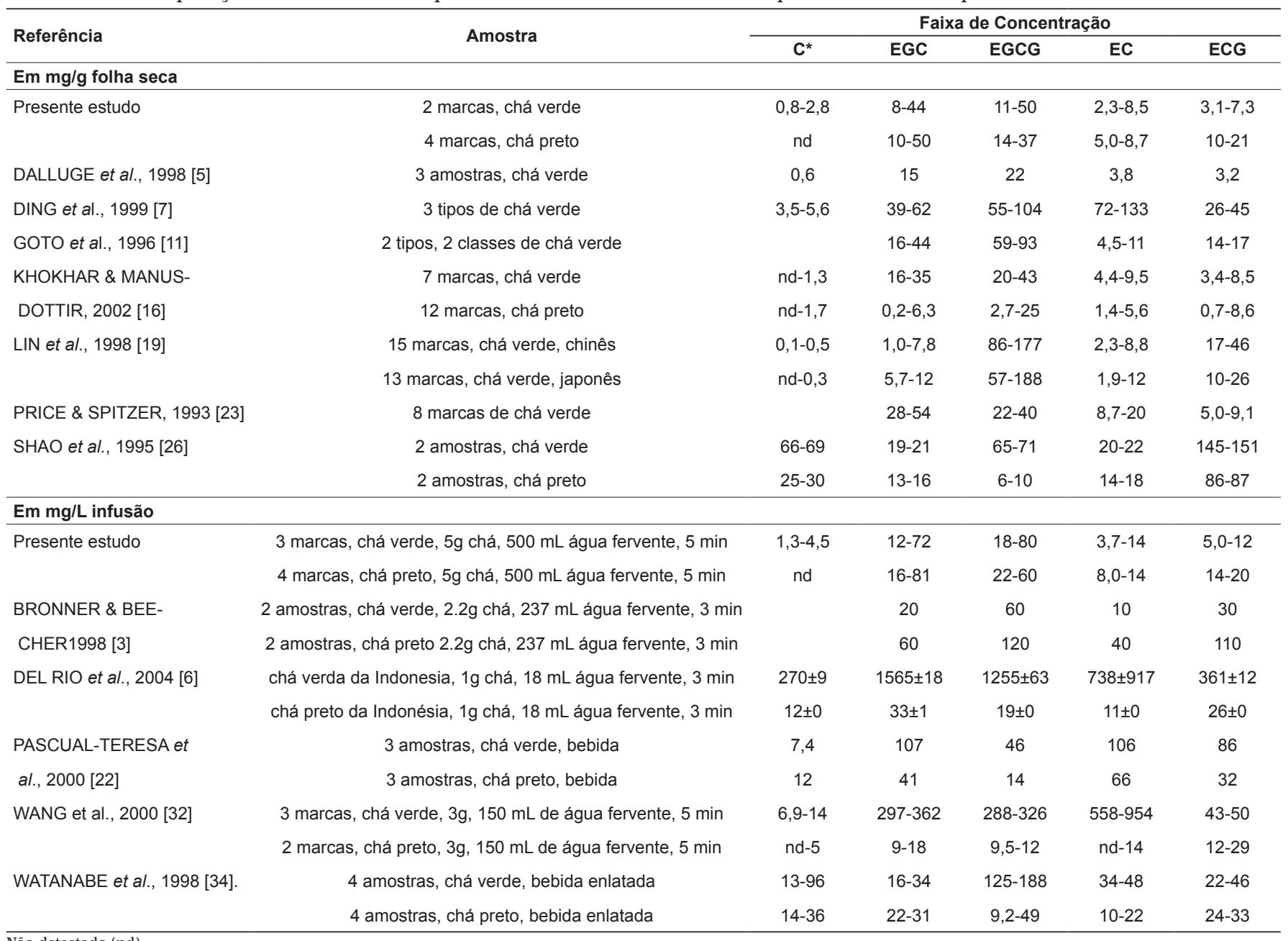

Não detectado (nd)

*(C) catequina; (EGC) epigalocatequina; (EGCG) epigalocatequina galato; (EC) epicatequina; (ECG) epicatequina galato. A C não foi relatada nas referências 3 , 11 e 23

verde e preto, mas nenhuma descrição das amostras foi apresentada, e se a unidade especificada ( $\mathrm{mg} / 100 \mathrm{~g}$ ) fosse correta, os teores seriam muito baixos.

A divergência entre os valores em $\mathrm{mg} / \mathrm{L}$ de infusão é ainda maior (Tabela 3), não tendo um perfil definido. Uma explicação para tal variação é o fato de que as infusões foram preparadas de maneiras diferentes, mas a variabilidade analítica também está envolvida. Os nossos resultados são mais parecidos aos do BRONNER \& BEECHER [3] para chá verde, com exceção de ECG que é menor no presente trabalho, e com os de DEL RIO et al. [6] para chá preto, com exceção de $\mathrm{C}$ que não foi detectado no nosso estudo. Os dados obtidos por DEL RIO et al. e por WANG et al. [32] para chá verde são muito superiores aos demais, embora DEL RIO et al. utilizaram apenas $18 \mathrm{~mL}$ de água fervente por $3 \mathrm{~min}$.

Os resultados em $\mathrm{mg} / \mathrm{g}$ de folha seca foram calculados com base nos resultados em $\mathrm{mg} / \mathrm{L}$ da infusão, levando em conta que $5 \mathrm{~g}$ da folha seca foram utilizados para fazê-la. Foi assumido que a água de infusão (nas condições usadas) extraiu eficientemente as catequinas das folhas. Conside- rando que as condições utilizadas no presente trabalho envolveram maior quantidade de água e maior tempo de exposição (Tabela 3), e ainda a concordância dos presentes resultados, em $\mathrm{mg} / \mathrm{g}$ de folha seca, com a maioria dos resultados publicados, esta suposição parece ser válida.

\section{3 - Teores de teaflavinas}

Observando-se o cromatograma na Figura 3, verificase uma sobreposição dos dois últimos picos referentes a teaflavina 3'-galato e a teaflavina 3-3'-digalato. Apesar de várias tentativas para melhorar a resolução destes dois compostos, não se obteve resultado melhor. Outros autores [1, 18, 26] publicaram seus cromatogramas em que mostravam a separação das quatro teaflavinas, com o mesmo perfil alcançado no presente trabalho, embora a fase móvel empregada contenha acetonitrila. A diferença entre a separação com fase móvel contendo metanol em relação à separação com fase móvel contendo acetonitrila foi a reversão da ordem de eluição de teaflavina 3-galato e a teaflavina, a teaflavina eluída primeiro na última fase. 


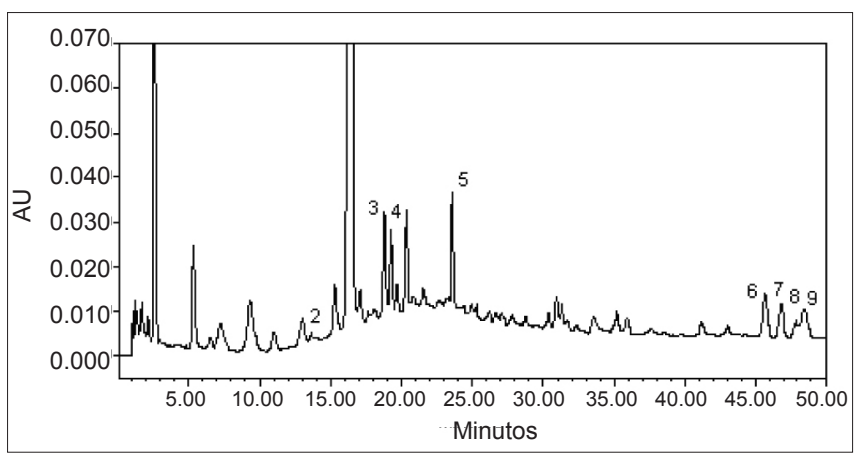

FIGURA 3 - Cromatograma de amostra de chá preto. Condições cromatográficas: Gradiente linear: $90 \% \mathrm{~A} / 6 \mathrm{~min}$, de 90 a $70 \% \mathrm{~A} / 14 \mathrm{~min}$, de 70 a $55 \% \mathrm{~A} / 20 \mathrm{~min}$, sendo $\mathrm{A}: \mathrm{H}_{2} \mathrm{O} /$ ác. fórmico (99,7:0,3, v/v) e B: MeOH/ác. fórmico (99,7:0,3, v/v) ; vazão 1,0 $\mathrm{mL} / \mathrm{min}$; detecção a $280 \mathrm{~nm}$. Picos: (2) epigalocatequina, (3) epigalocatequinagalato, (4) epicatequina, (5) epicatequinagalato, (6) teaflavina 3-galato, (7) teaflavina, (8) teaflavina 3'-galato e (9) teaflavina 3-3'-digalato

Os trabalhos em que foram determinados teores de teaflavinas são escassos. As concentrações das amostras analisadas no presente trabalho apresentam-se superiores às de SHAO et al. [26], que variam de 1,3 a 4,8 mg/g e ao valor de teaflavinas totais de LEE \& ONG [18] de aproximadamente $1 \mathrm{mg} / \mathrm{g}$.

Utilizando a mesma metodologia de análise e quantificação, foi verificada a presença de catequinas e teaflavinas em nove tipos de chás muito consumidos no Brasil, dentre eles, chás de ervas (erva-mate, mate, erva cidreira, erva doce, hortelã, boldo), de flores (camomila) e de frutas (morango e maçã). Em nenhuma das amostras foi encontrada alguma catequina ou teaflavina.

\section{4 - REFERÊNCIAS BIBLIOGRÁFICAS}

[1] BAILEY, R.G.; MCDOWELL, I.; NURSTEN, H.E. Use of HPLC photodiode-array detector in a study of the nature of a black tea liquor. J. Sci. Food Agric., v. 52, n. 2, p. 509-525, 1990.

[2] BALENTINE, D.A.; WISEMAN, S.A.; BOUWENS, L.C.M. The chemistry of tea flavonoids. Crit. Rev. Food Sci. Nutr., v. 37, n. 8, p. 693-704, 1997.

[3] BRONNER, W.E.; BEECHER, G.R. Method for determining the content of catechins in tea infusions by highperformance liquid chromatography. J. Chromatogr. A., v. 805, n. 1-2, p. 137-142, 1998.

[4] COLLIER, P.D.; BRYCE, T.; MALLOWS, R.; THOMAS, P.E.; FROST, D.J.; KORVER, O.; WILKINS, C.K. The theaflavins of black tea. Tetrahedron, v. 29, n. 1 , p. 125-142, 1973.

[5] DALLUGE, J.J.; NELSON, B.C.; THOMAS, J.B.; SANDER, L.C. Selection of column and gradient elution system for the separation of catechins in green tea using high-performance liquid chromatography. J. Chromatogr. A., v. 793, n. 2, p. 265-274, 1998.

[6] DEL RIO, D.; STEWART, A.J.; MULLEN, W.; BURNS, J.; LEAN, M.E.J.; BRIGHENTI, F.; CROZIER, A. HPLC-MS analysis of phenolic compounds and purine alkaloids in green and black tea. J. Agric. Food Chem., v. 52, n. 10, p. 2807-2815, 2004.

[7] DING, M.; YANG, H.; XIAO, S. Rapid, direct determination of polyphenols in tea by reversed-phase column liquid chromatography. J. Chromatogr. A., v. 849, n. 2, p. 637-640, 1999.

[8] DREOSTI, I.E. Bioactive ingredients: antioxidants an polyphenols in tea. Nutr. Rev., v. 54, n. 11 (Part II), p. s51-s58, 1996.

[9] DUFRESNE, C.; FARNWORTH, E. Tea, kombucha, and health: a review. Food Res. Inter., v. 33, n. 6, p. 409-421, 2000.

[10] FUJITA, Y.; YAMANE, T.; TANAKA, M.; KUWATA, K.; OKUZUMI, J.; TAKAHASHI, T.; FUJIKI, H.; OKUDA, T. Inhibitory effect of (-)-epigallocatechin gallate on carcinogenesis with N-ethyl-N'-nitro-N-nitrosoguanidine in mouse duodenum. Jpn. J. Cancer Res., v. 80, p. 503-505, 1989.

[11] GOTO, T.; YOSHIDA, Y.; KISO, M.; NAGASHIMA, H. Simultaneous analysis of individual catechins and caffeine in green tea. J. Chromatogr. A., v. 749, n. 1-2, p. 295-299, 1996.

[12] HERTOG, M.G.L.; HOLLMAN, P.C.H.; van de PUTTE, B. Content of potentially anticarcinogenic flavonoids of tea infusions, wines and fruit juices. J. Agric. Food Chem., v. 41, n. 8, p. 1.242-1.246, 1993.

[13] HEIM, K.E.; TAGLIAFERRO, A.R.; BOBILYA, D.J. Flavonoid antioxidants: Chemistry, metabolism and structure-activity relationships. J. Nutr. Biochem., v. 13, n. 10, p. 572-584, 2002.

[14] HIGDON, J.V.; FREI, B. Tea catechins and polyphenols: Health effects, metabolism, and antioxidant functions. Crit. Rev. Food Sci. Nutr., v. 43, n. 1, p. 89-143, 2003.

[15] HO, C.; CHEN, Q.; SHI, H.; ZHANG, K.; ROSEN, R.T. Antioxidative effect of polyphenol extract prepared form various Chinese teas. Prev. Med., v. 21, n. 4, p. 520-525, 1992.

[16] KHOKHAR, S.; MAGNUSDOTTIR, S.G.M. Total phenol, catechin, and caffeine contents of teas commonly consumed in the United Kingdom. J. Agric. Food Chem., v. 50, n. 3, p. 565-570, 2002.

[17] KURODA, Y.; HARA, Y. Antimutagenic and anticarcinogenic activity of tea polyphenols. Mut. Res./Fund. Mol. Mech. Mut., v. 436, p. 69-97, 1999.

[18] LEE, B.; ONG, C. Comparative analysis of tea catechins and theaflavins by high-performance liquid chromatography and capillary electrophoresis. J. Chromatogr. A., v. 881, n. 1-2, p. 439-447, 2000.

[19] LIN, J.-K.; LIN, C.-L.; LIANG, Y.-C.; LIN-SHIAU, S.-Y.; JUAN, I.-S. Survey of catechins, gallic acid and methylxantines in green, oolong, pu-erh and black teas. J. Agric. Food Chem., v. 46, n. 9, p. 3.635-3.642, 1998.

[20] MATTILA, P.; ASTOLA, J.; KUMPULAINEN, J. Determination of flavonoids in plant material by HPLC with diode-array and electro-array detections. J. Agric. Food Chem., v. 48, n. 12, p. 5.834-5.841, 2000.

[21] NISHIDA, H.; OMORI, M.; FUKUTOMI, Y.; NINOMIYA, M.; NISHIWAKI, S.; SUGANUMA, M.; MORIWAKI, H.; MUTO, Y. Inhibitory effects of (-)-epigallocatechin gallate on spontaneous hepatoma in $\mathrm{C} 3 \mathrm{H} / \mathrm{HeNCrj}$ mice and 
human hepatoma-derived PLC/PRF/5 cells. Jpn. J. Cancer Res., v. 85, p. 221-225, 1994.

[22] PASCUAL-TERESA, S.; SANTOS-BUELGA, C.; RIVASGONZALO, J.C. Quantitative analysis of flavan-3-ols in Spanish foodstuffs and beverages. J. Agric. Food Chem., v. 48, n. 11, p. 5.331-5.337, 2000.

[23] PRICE, W.E.; SPITZER, J.C. Variations in the amounts of individual flavanols in a range of green teas. Food Chem., v. 47, n. 3, p. 271-276, 1993.

[24] RICE-EVANS, C.A.; MILLER, N.J.; PAGANGA, G. Antioxidant properties of phenolic compounds. Trends Plant Sci., v. 2, n. 4, p. 152-159, 1997.

[25] RODGERS, E.H.; GRANT, M.H. The effect of the flavonoids, quercetin, myricetin and epicatechin on the growth and enzyme activities of MCF7 human breast cancer cells. Chem.-Biol. Interactions, v. 116, n. 1-2, p. 213-228, 1998.

[26] SHAO, W.; POWELL, C.; CLIFFORD, M.N. The analysis by HPLC of green, black and pu'er teas produced in Yunnan. J. Sci. Food Agric., v. 69, n. 4, p. 535-540, 1995.

[27] SKIBOLA, C.F.; SMITH, M.T. Potential health impacts of excessive flavonoid intake. Free Radic. Biol. Med., v. 29, n. 3-4, p. 375-383, 2000.

[28] SUGANUMA, M.; OKABE, S.; SUEOKA, N.; SUEOKA, E.; MATSUYAMA, S.; IMAI, K.; NAKACHI, K.; FUJIKI, H. Green tea and cancer chemoprevention. Mut. Res./ Rev. Mut. Res., v. 428, n. 1-2, p. 339-344, 1999.

[29] TAKEO, T. Green tea and semi-fermented teas. In:
WILSON, K.C.; CLIFFORD, M.N. (eds.) Tea: Cultivation to consumption., London: Chapman and Hall, 1992, p. 413-414

[30] TIJBURG, L.B.M.; MATTERN, T.; FOLTS, J.D.; WEISGERBER, U.M.; KATAN, M.B. Tea flavonoids and cardiovascular diseases: a review. Crit. Rev. Food Sci. Nutr., v. 37, n. 8, p. 771-785, 1997.

[31] VISIOLI, F.; BORSANI, L.; GALLI, C. Diet and prevention of coronary heart disease: the potential role of phytochemicals. Cardiov. Res., v. 47, n. 3, p. 419-425, 2000.

[32] WANG, H.; HELLIWELL, K.; YOU, X. Isocratic elution system for the determination of catechins, caffeine and gallic acid in green tea using HPLC. Food Chem., v. 68, n. 1, p. 115-121, 2000.

[33] WANG, H.; PROVAN, G.J.; HELLIWELL, K. Tea flavonoids: their functions, utilization and analysis. Trends Food Sci. Tech., v. 11, n. 4-5, p. 152-160, 2000.

[34] WATANABE, T.; NISHIYAMA, R.; YAMAMOTO, A.; NAGAI, S.; TERABE, S. Simultaneous analysis of individual catechins, caffeine, and ascorbic acid in commercial canned green and black teas by micellar electrokinect chromatography. Anal. Sci., v. 14, n. 2, p. 435-438, 1998.

\section{5 - AGRADECIMENTOS}

À Capes pela concessão de bolsa à primeira autora e à Fapesp pelo financiamento do projeto Pronex Processo $n^{\circ} 2003 / 10151-4$. 